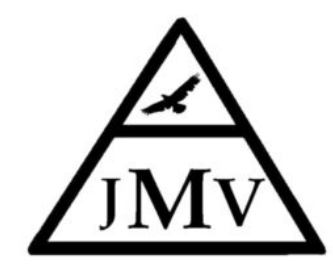

\title{
Editorial
}

\section{Remotely controlled ventilators, it is time} Ehab G Daoud MD ${ }^{1}$

DOI: $10.5281 /$ zenodo. 4244998

Cite: Daoud EG. Remotely controlled ventilators, its time. J Mech Vent 2020; 1(2):55-56.

In this issue we read with interest the article by Cabbat and Cho explaining the benefits of implementing wireless technology to control mechanical ventilators. In full agreement with them, especially in this unprecedented time where we are confronted in the ICU with a highly infectious virus, I think the time has come for us to be able to control the ventilator remotely, at least from the outside of the patient room. In this era of COVID-19 underscored by a shortage of clinicians and PPEs, this remotely controlled ventilator makes so much sense for all the reasons they highlighted.

Additionally, in our current era of technological advances, almost any devices we use in our daily life has the option of being remotely controlled. Imagine purchasing a television and having to manually change and pick among channels much like we did 40 years ago.

The idea of monitoring and controlling the mechanical ventilator is not totally novel. In 2009, Dellaca' and colleagues ${ }^{1}$ published a study about a wireless technology that can monitor and control a home mechanical ventilator. In 2016, Seddik and colleagues ${ }^{2}$ published a similar paper about controlling three different hospital ventilators remotely as well.
Earlier this year, we published a report where we modified the ICU rooms and were able to get the ventilator CPU monitor outside the patients' room ${ }^{3}$ (figure 1) in an effort to reduce and limit exposure to highly infectious pathogens and viruses for the same reason Cabbat mentions in his article.

Recently, researchers from the Northwestern university ${ }^{4}$ and John Hopkins ${ }^{5}$ have developed systems that can control their ventilators remotely without entering the patients' rooms. Medtronic, a ventilator manufacturer is currently rolling out free upgrades that will allow each of its ventilators to be controlled from a dedicated device outside of the isolation room. ${ }^{6}$

We have learnt a lot during this pandemic and there are still places for more learning and innovation. With the advance of mechanical ventilator systems, this technology will find its way in the next generation ventilators.

Author

1. Ehab G Daoud, MD, FACP, FCCP. Associated professor of Medicine, John A Burns School of Medicine, Hawaii, USA and director of respiratory care program, Kapiolani Community College, Hawaii, USA

Corresponding author: ehab_daoud@hotmail.com

Conflict of interest/Disclosure: None

Funding: None

This open-access article is distributed under the terms of the Creative Commons Attribution Non-Commercial License (CC BY-NC) (http://creativecommons. $\mathrm{org} /$ licenses/by-nc/4.0/), which permits reuse, distribution and reproduction of the article, provided that the original work is properly cited and the reuse is restricted to noncommercial purposes. For commercial reuse, contact: editor.JMV@gmail.com 


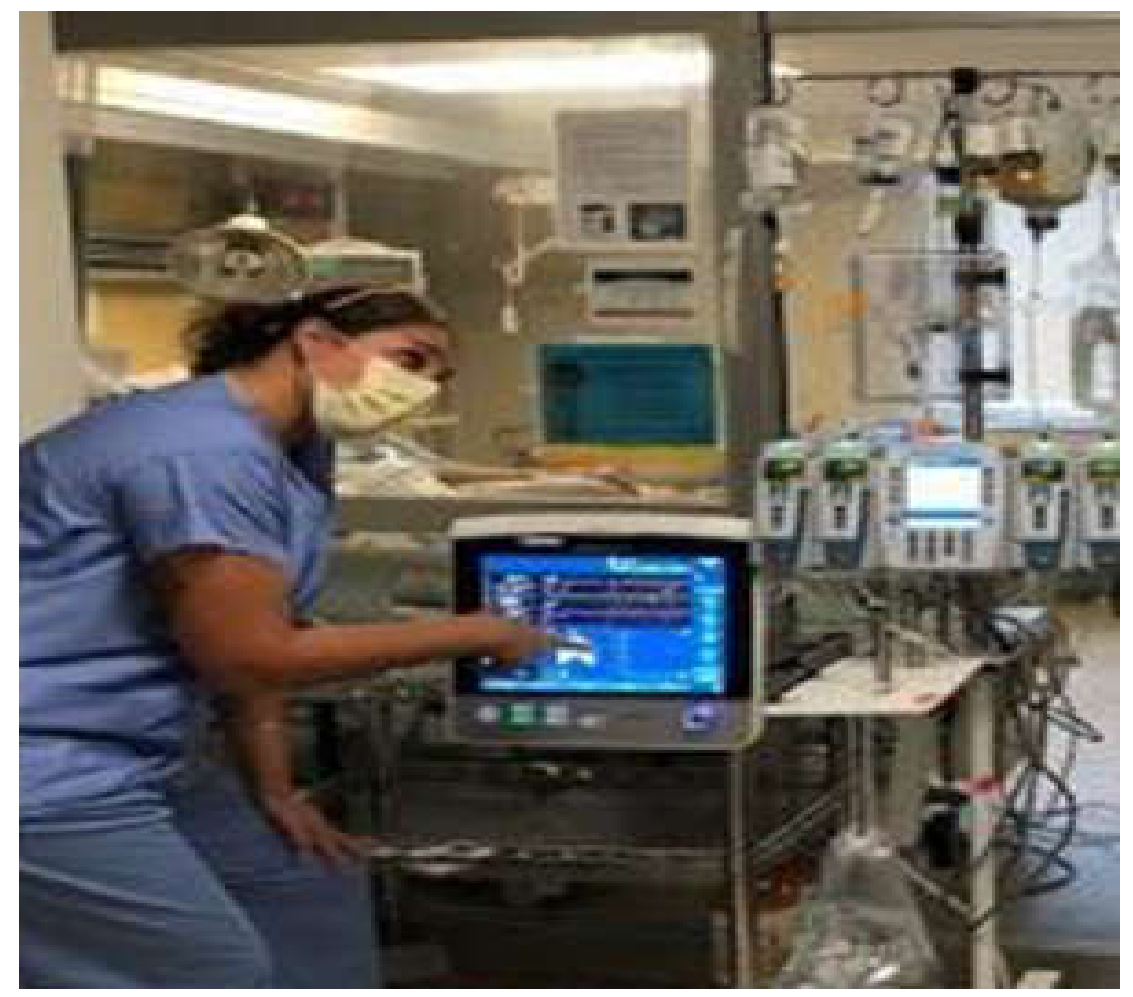

Figure 1

Ventilator CPU monitor outside the patient room and connected with wire cable to the ventilator inside the room

\section{References}

1. Dellaca' RL, Gobbi A, Govoni L, et al. A Novel Simple Internet-Based System for Real Time Monitoring and Optimizing Home Mechanical Ventilation. International Conference on eHealth, Telemedicine, and Social Medicine 2009; 209-215

2. Seddik H, Eldeib AM. A wireless real-time remote control and tele-monitoring system for mechanical ventilators. 8th Cairo International Biomedical Engineering Conference (CIBEC) 2016; 64-67.

3. Su M, Shokry M, Daoud E. Modifying icu rooms to protect health care workers during the COVID 19 Crisis: Brief Report. Clinical and Experimental Investigations 2020; 1(2):1-3.
4. Invention Helps Limit Exposure to Infection, accessed 11/2/2020 at https://www.nm.org/healthbeat/medicaladvances/covid-19-advances-incare/anesthesiologist-develops-system-for-remotecontrol-of-ventilators.

5. remote control for COVID-19 patients ventilators, accessed 11/2/2020 at https://hub.jhu.edu/2020/08/13/remote-controlventilators-covid-19-pandemic/

6. Medtronic deploys remote-controlled ventilators to lessen coronavirus exposure, accessed 11/2/2020 at https://www.fiercebiotech.com/medtech/medtronicdeploys-remote-controlled-ventilators-to-lessencoronavirus-exposure 